\title{
Research on Promoting the Construction of Online Government Service Platform with Standardization
}

\author{
Xiao Wen $\mathrm{XU}^{*}$ Li Ying \\ China National Institute of Standardization, No. 4 Zhichun Road, Beijing, China
}

\begin{abstract}
The standardization of the online government service platform is of great significance to simplify the procedures and improve the efficiency of administrative licensing agencies. In this paper, the definition of online government service platform, from the law, policy background, the practice level, carry out the work of government services online analysis summarizes the necessity, the role of online government service platform and the existing problems, and analysis the reasons from the dimension of standardization, standardization can be targeted to summarize proposed online government service platform construction of three aspects of the role.
\end{abstract}

Keywords: Research, Online Government Services Platforms, standardization

\section{Introduction}

An online government services platform is a vetting administration platform that integrates application, data exchange, approval, supervision, inquiry and other services, providing companies and the public with one-stop service in an efficient, transparent and standardized way. Totally different from traditional vetting administration mode, it is based on modern Internet and data technologies, creating an innovative workplace. It demonstrates the restructuring and optimization of vetting structure and process and removes temporal, spatial and division restrictions.

Article 33 of Administrative Licensing Law of the People's Republic of China states that "administrations shall establish and improve related systems, introduce E-government practices, post licensing items on their websites and enable the submission of e-application for administrative licensing".

Since 2015, the State Council issued a series of documents, which focused on the reform of administrative licensing system as an offensive move for the transformation of government functions and a central cannon for administration streamlining and power delegating. In Jan. 2017, Notification of Issuing and Distributing Guidelines for Building 'Internet + Government Service' Technologies System by General Office of the State Council (Guo Ban Han (2016) No. 108) (hereinafter referred to as No. 108) was distributed

*Corresponding author: xuxw@cnis.ac.cn, 420655022@.qq.com 
to address such issues as an incomplete set of services, insufficient information sharing, low rate of acceptance and inconvenient services for companies and the public;Notification of Sharing General Information on Citizens, Enterprises, Institutions and Social Organizations Contained in Administrative Licenses by State Commission Office of Public Sectors Reform (Administrative Examination and Approval Reform Office of the State Council), National Development and Reform Commission and Ministry of Public Security issued and distributed in Feb. 2017 and Implementation Programme of Integrating and Sharing Information on Government Affairs issued and distributed in May 2017 specifies information sharing for online government services; The State Council's Advices on Quality Improvement Move issued and distributed in Sep. 5, 2017 states that we shall “ improve social governance and public service, introduce 'Internet + Government Service', speed up the standardization of administrative licensing system, optimize work flow, streamline administrative process and increase efficiency"; Passed at the first meeting of the Central Reform Commission presided by Chairman Xi Jinping in March 2018, Advices on Furthering Convenient Vetting Services hold a principle of " integrating institutional innovation and "Internet + Government Service"" . At the videophone conference on deepening the reform of streamlining administration, delegating powers and improving regulation and services to transform government functions on June 28, 2018, Prime Minister Li Keqiang instructed that we shall " enable companies and the public to go through administrative procedures without asking for a favor, continue with less licenses and convenient services move, reinforce clean-up, reduction and merging, develop 'Internet + Government Services' and facilitate the integration of online and offline operation".

In conclusion, the mentioned documents above by those agencies reveal the necessity and urgency of building online government services platforms.

\section{Application}

In recent years, a few local governments have gained experience from persistent, innovative efforts. Zhejiang Province introduced the practice of At Most Once to allow data to be shared rather than being isolated, improve "Internet + Government Services" design at top level and build a comprehensive government service network across Zhejiang using methodology of systems engineering. It also introduced "Non-face-to-face Vetting" and "Online Procedures", which integrate all government service networks of 65 agencies under Zhejiang government and at metropolitan and county level into a single government service network and thus allow information systems for government affairs to be interconnected. In June 2017, Jiangsu Government Service website was launched to ensure that all applications submitted for approval at provincial, metropolitan and county level are addressed as reasonable as possible. By the end of 2017, majority of applications to administrations at provincial, metropolitan and county level had been addressed online, a change from face-to-face to key-to-key. Wuhan in Hubei Province introduced the practice of Right Now, Online and Just Once. In response to the mandate of enabling online operation to be normality and offline one to be an exception, it gave priority to online operation and built a unique ID certification system and a government-specific big data center across Wuhan. In conclusion, these practices reveal that administrative licensing agencies preferred online government services platforms in streamlining process and increasing efficiency. 


\section{Role}

\subsection{Less cost and higher efficiency is an important move for a saving and efficient government}

Online government services platforms help reduce bureaucratic procedures frequently occurring offline, get rid of disadvantages of inefficient administration such as excessive paper work and meetings and lower government's operating costs. They have changed the situation of each vetting agency operating on its own way into sharing information and cooperating with each other. With vetting procedures optimized and rebuilt, they served the purpose of shortening timeline、 cost saving and increasing efficiency

for example, Agriculture in China new veterinary drug registration for examination and approval matters need to submit each evaluation 30 sets of paper material, material printing costs 10000 yuan, agricultural Agriculture in China integrated office system of administrative examination and approval and the veterinary drug evaluation system has realized the paperless review after connected, saved a review of 30 sets of tens of thousands of yuan for the print paper material, new veterinary drug registration for examination and approval matters in accordance with the transferred to an average of 120 items a year, every year for the enterprise to save material printing costs an average of 1.2 million yuan of above.

\subsection{Integrating information and resources and publicizing government affairs is a path to a transparent and fair government}

Online government services platforms enable transparent procedures for administrative licensing all around, from directory of items under administrative licensing, terms and conditions and procedures to licensing process and measures, which allow licensing-related activities to be supervised by applicants and the public for open and transparent purpose.

\subsection{Improving technical regulations and administrating according to the law is a warrant for an honest government based on the rule of law}

Licensing procedures and legal documents as stipulated in the Administrative Licensing Law and Guidelines for Standardization of Administrative Licensing may be established via online government services platforms. The Administrative licensing agencies have to operate accordingly. Administrative activities violating these procedures are significantly reduced. With accountability, authority, responsibility, and timelines identified, the licensing process is standardized. Additionally, applicable conditions as stipulated in related laws and regulations, including documents, timelines and fees relating to administrative licensing, may be embedded, so as to reduce omission and illegal act and alert errors.

\section{Issues about online government services platforms and their causes from the perspective of standardization}

\subsection{Rushing forward, operating on its way, duplication and serious waste}

At the national level, the top-level design scheme for the overall construction of the government service platform has been issued, and the mandatory requirements such as the 
time limit and process of the administrative license work have been continuously increased. However, the foundation of the government service platform construction in different regions is inconsistent, and the national top-level design scheme cannot accurately guide the specific practice in different regions. local administrations have to move existing offline operation to online one without any change in mode of operation and an online government services platform in one area may not affect those in other areas. As a result, duplication occurs.

Causes are that unified planning and reasonable deployment is not made at early stage of online government services platform building. Rushing into building these platforms leads to waste and duplication.

\subsection{Imbalance, "best game no one played" and even eye candy}

Different schedules and design whereby individual online government services platforms were built, different materials required for the same subject matter and different deadlines caused difficulties in coordinated licensing and insufficient licensing via online government services platforms.

Causes are that independent operation and fragmentation are impairing the power of online government services platforms. Even in the same urban district and for the same item, it is impossible to unify item name, materials to be submitted and process and coordinate information or information systems, which is one of causes that online government services platforms are the best game no one played.

\subsection{Simple services}

Incomplete functionality and simple services lead to online acceptance, vetting, decision, payment and delivery being not realized but provision of general information and receipt of applications. These platforms do not serve the purpose of integrating online and offline operation as expected. Applicants still have to go through online and offline procedures for the same subject matter.

Causes are that it is undesirable to move offline administrative licensing as a whole to online one. What is feasible for offline licensing may not be the case for online one, for example, trans-department and cross-level licensing.

\section{Role of standardization in building online government services platforms}

\subsection{Essential foundation and support}

The starting point of setting standards is to "obtain the best order", "promote the best common benefit" and "promote standardization by standardization". The basic system tool of standards can also play its role in online administrative licensing.

\subsubsection{Existing deliveries of administrative licensing standardization are applied to online government services platforms to make online government services in line with compliance requirement}

Existing deliveries of administrative licensing standardization are applied to online government services platforms to make online government services in line with compliance requirement. Like offline government services, online ones shall be delivered in accordance 
with general requirements of Guidelines for Standardization of Administrative Licensing (2016) and No. 108. Deliveries of offline government service standardization such as items, work flow and services relating to administrative licensing are applied to online government services to make them in line with these documents. For instance, such provisions as "acceptance forms or receipts shall be issued within 5 days after applications for administrative license are submitted" and "decisions about administrative licensing shall be posted online according to the law" may be embedded into the work flow of online government services to make these services in line with compliance requirements.

\subsubsection{Elements and work flow for an item are standardized for coordination purpose}

Items are identified according to the rule of Minimum Granularity. The name, justification, code, deadline, required materials, qualification for acceptance, qualification for approval, procedures, results document name of any item are standardized based on the principle of The Same Item, Standard, Code and Process, Minimum Granularity. This standardizing move lays the groundwork for the integrated vetting on online government services platforms and in turn enables Three-level Linkage or Five-level linkage between administrative licensing at provincial, metropolitan, county, town and village level. It eventually leads to "any application, even from area other than your own one, can be accepted via the nearest platform in the same city."

\subsection{Higher service quality}

Give full play to the forward-looking guidance function of standards in online administrative licensing to help standardize the management of administrative licensing items and reduce and optimize the process.

\subsubsection{Apply the standardization research results to the construction of online government service platform}

Administrative Licensing Items Classification and Coding Rules under research specify rules and methodology for coding administrative licensing items. These rules ensure that each item has a unique identification, which facilitates not only administrative licensing management and implementation but also administrative licensing-related information systems building. Instead of separating information, they allow data statistics, comparison, analysis and application in response to needs for interconnection between information systems and resources sharing.

\subsubsection{Results under research are applied to online government services platform building to guide the optimization of online government services process}

It is undesirable to move offline administrative licensing apply mechanically online one. The former shall be refined in line with online scenario. Administrative Licensing Process Optimization Methodology \& specifications under development provide guidelines for identifying, renovating and refining online administrative government service progress.

\subsection{Guidance on evaluation}

Performance requirements for online administrative licensing are developed to guide online government services platform building. Provisions of No. 108 and compliance requirements 
of Guidelines for Standardization of Administrative Licensing dealing with administrative licensing may be integrated into these performance requirements.

\subsubsection{Standardizing online government services platform}

Performance requirements for online administrative licensing enable administrations to plan and deploy online government services platforms in a unified way, identify roadmap to growth, eliminate independent operation, duplication and imbalance and lay the foundation for online administrative licensing interconnection and information sharing.

\subsubsection{Efficient online services. Performance requirements for online administrative licensing provide self-inspection and inspection guidelines for online government services platforms}

They facilitate tracking and evaluating performance online, identifying and correcting problems and refining online government services platforms and their processes.

\section{Acknowledgements}

This article in this phase is part of a state-funded key research program, namely, Research on standardization of Press, Publication, Radio, Film and Television Administrative License work (No.572018Z-6569).

\section{References}

1. J H Li, Analysis of Issues from Online Administrative Vetting and Measures in China, Tianjin's Economics, 12, 35-37 (2013)

2. Ouyang Keli, Study on Chinese Online Administrative Vetting Building: Example of Area Q [D], Public Administration School, Nanchang University, Jiangxi

3. H Qin, Study on Reform of Chinese Administrative Vetting Mode: Based on Practices of Administrative Service Centre [D], Jilin University, Jilin 133-137(2011)

4. X Han, Thinking and Advices on Standardization of Guangdong Administrative Licensing Item Vetting [J], Standard Science, 5 (2017)

5. SN Ying. Contemporary Chinese Administrative Law (Vol)[M]. Beijing: Founder Press, China ,735 (2005)

6. C T Li. General introduction to standardization (6th edition) [M]. Beijing: Renmin University Press, 48(2014)

7. Unger, law in modern society, translated by wu yuzhang and zhou hanhua, China university of political science and law press, p 43 (1994)

8. H B Long, X J Wang. Dividends and performance evaluation of administrative approval reform: 2013-2015. China development press, p 98 (2016) 